\title{
Whipping properties of recombined, additive-free creams
}

\section{J. Andrade (1) and D. Rousseau* (-)}

Department of Chemistry and Biology, Ryerson University, Toronto, ON M5B 2K3, Canada

\begin{abstract}
There is increasing industrial interest in the use of the milkfat globule membrane as a food ingredient. The objective of this research was to determine whether the aerosol whipping performance of cream separated into butter and buttermilk, and then recombined, would perform in a manner similar to untreated cream. Churning of cream tempered to different solid fat contents was used to separate butter from buttermilk, which were then recombined at the same ratios as the initial extraction yield, or with $25 \%$ extra buttermilk. Differences in milkfat globule size distributions among the recombined creams were apparent; however, their whipping behavior and overrun were similar. Importantly, all recombined creams did not yield properties similar to the original cream, indicating that the unique native milkfat globule membrane structure plays a role in cream performance well beyond its simple presence.
\end{abstract} Key words: whipping cream, milkfat globule membrane, structure, churning, recombination

\section{INTRODUCTION}

Whipping cream is an oil-in-water emulsion that consists of 30 to $40 \%$ milkfat dispersed as globules $\sim 1$ to $15 \mu \mathrm{m}$ in diameter (Singh and Gallier, 2017). The milkfat globule membrane (MFGM), which is a phospholipid-rich membrane that harbors different membrane proteins, is critical to the integrity and stability of the dispersed globules (Evers, 2004a,b; Lopez et al., 2019). The MFGM is of considerable interest to the dairy industry given its potential as a food ingredient in applications that include emulsion formation, texture control, and whipping performance.

Broadly described, whipping involves the incorporation of air into chilled cream via mechanical agitation. Cooling cream to a temperature below the crystalliza-

Received September 10, 2020.

Accepted February 6, 2021.

*Corresponding author: rousseau@ryerson.ca tion temperature of some of the milkfat triacylglycerols results in the partial solidification of the globules, which then play a critical role in foam formation and stabilization. Mechanistically, newly created air-water interfaces arising from air incorporation will initially be stabilized by $\beta$-casein (Goff, 1997), which will result in a 3-dimensional skeleton of coarse bubbles. Partially crystallized milkfat globules will adhere to the network of the newly formed bubbles, with the solid fat causing the rupture of the MFGM and the gradual formation of a network of partially coalesced globules around the bubbles (Brooker et al., 1986; Boode et al., 1993; Goff, 1997). With continued whipping, further partial coalescence will occur and eventually, a space-filling 3-dimensional network will form, connecting neighboring air bubbles dispersed within the aqueous phase (Wasan et al., 2004; Hotrum et al., 2005).

Factors that affect whipped cream foam integrity include temperature treatments, added ingredients, and shear. The temperature treatment that a cream is subjected to, as well as the solid fat content (SFC) of the cream before mixing, will greatly affect whipping time and overrun (Moens et al., 2016), as well as the kinetic stability of the resulting foam bubbles (MéndezVelasco and Goff, 2011; Truong et al., 2014a). In creams containing external stabilizing agents such as proteins, surfactants, hydrocolloids, or other lipids, air bubbles may be also stabilized via physical jamming of the fat globules, depending on the globule diameter, ratio of surfactant and protein present in the continuous phase, and tempering cycles (Thivilliers et al., 2008; Fuller et al., 2015a,b). Once formed, the subsequent thinning of liquid lamellae separating adjacent air bubbles will result in breakdown. Adding hydrocolloids (Dickinson, 2009), increasing the levels of fat adsorption at the air-water interface (Truong et al., 2014a), or raising cream SFC may slow bubble drainage, coalescence, and disproportionation (Ostwald ripening of gas bubbles; Méndez-Velasco and Goff, 2011; Truong et al., 2014a). Finally, if foaming is performed in conditions that exceed the optimal overrun, partially solidified milkfat globules will aggregate, eventually leading to phase inversion and butter formation (Buldo et al., 2013; Panchal et al., 2017). 


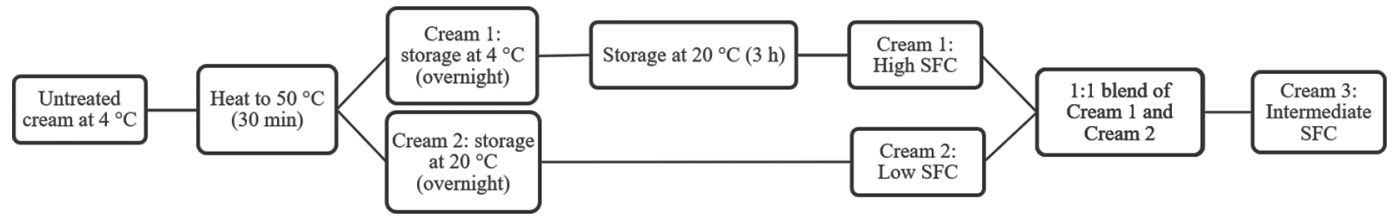

Figure 1. Temperature treatments used to obtain creams with different solid fat content (SFC) values.

Butter-making results in the separation of crystalline milkfat as butter grains and buttermilk, and depends on many factors, such as cream aging and processing conditions. During continued churning of the newly formed butter mass, remaining milkfat globules will be subjected to more extensive destabilization and MFGM stripping, and therefore, more MFGM material will be entrained in the associated buttermilk (Corredig et al., 2003; Fox and McSweeney, 2006; Tamime, 2009). Churning conditions and initial SFC will also dictate the final butter and buttermilk yields (Boode et al., 1993; Buldo et al., 2013).

Recombination of milkfat [usually as anhydrous milkfat (AMF)] with skim milk solids (often as milk powders) is a useful and common technology to make a wide range of milk products. Examples include recombined whole milk, creams, and cultured products, such as yogurt and sour cream, among others. However, such recombined products seldom match the properties of products made directly from fresh milk, which results from dissimilar compositions given the loss of MFGM components during AMF manufacture. Numerous groups have investigated the addition of MFGM material (e.g., as buttermilk powder) back into recombined products to better match their fresh milk counterparts (Scott et al., 2003; van Lent et al., 2008; Phan et al., 2014). Although partly successful, the properties of recombined products were subpar compared with the products made with fresh milk. Even with addition of MFGM material, compositions were not equivalent or, more importantly, the original MFGM structure was not recreated.

The goal of this research was to compare the emulsion properties and aerosol whipping performance of recombined versus a control cream. Churned cream tempered to different SFC was separated into butter and buttermilk, and then recombined at the same ratios as the initial extraction yield, or with $25 \%$ extra buttermilk. Specific objectives included investigation of cream structuring via tempering to different SFC, as well as characterization of recombined cream with or without added buttermilk, and how this approach affected aerosol whipped cream formation and stability.

\section{MATERIALS AND METHODS}

Pasteurized, unhomogenized cream (35 wt\% fat) processed in Guelph, ON, Canada, was obtained from a local supermarket and stored at $4^{\circ} \mathrm{C}$.

\section{Recombined Cream Preparation}

The untreated cream was heated to $50^{\circ} \mathrm{C}$ for $30 \mathrm{~min}$ to remove any solid fat that might influence subsequent milkfat crystallization. The heated cream was separated in 2 aliquots to target different SFC. The first aliquot was kept at $4^{\circ} \mathrm{C}$ overnight to form the higher SFC variant [cream 1 (C1)]. A second aliquot was kept at the room temperature $\left(20^{\circ} \mathrm{C}\right)$ to produce the variant with a lower SFC [cream $2\left(\right.$ C2)]. After $15 \mathrm{~h}$ at $4^{\circ} \mathrm{C}$, $\mathrm{C} 1$ was brought to room temperature and held for $3 \mathrm{~h}$, after which equal parts of $\mathrm{C} 1$ and $\mathrm{C} 2$ were mixed to form the third variant [cream 3 (C3)], which had an intermediate SFC. An untreated cream sample was used as the control. Figure 1 summarizes the temperature treatments of the creams.

Samples (100 g) of C1, C2, and C3 were worked at room temperature using a handheld mixer with one whisk at maximum power (250W; Black \& Decker). The butter and buttermilk from the resulting treatments, whose yields were quantified on a total mass basis, were recombined at 1 of 2 wt $\%$ ratios. For ratio 1 (R1), the buttermilk and butter were recombined as per the yields obtained during churning, which corresponded to buttermilk:butter ratios of 55:45, 65:35, and 57:43 for C1, C2, and C3, respectively. For ratio 2 (R2), only 75 wt\% of the total butter obtained during churning was used. Extra buttermilk obtained from the same cream treated in the same way was added to match the starting mass of R1. With this approach, R2 buttermilk:butter ratios were $66.25: 33.75$ for $\mathrm{C} 1$, 73.25:26.25 for $\mathrm{C} 2$, and 67.75:32.25 for C3.

To recombine the butter and buttermilk, the extracted butter was heated to $60^{\circ} \mathrm{C}$, and then buttermilk kept at room temperature was added. The resulting mixture was subjected to high-shear mixing (Polytron PT 2500 E, Kinematica, Inc.) at 10,000 rpm for $1 \mathrm{~min}$. The re- 
sulting emulsion at $\sim 55^{\circ} \mathrm{C}$ was cooled in a $4^{\circ} \mathrm{C}$ walk-in refrigerator to a temperature of $20^{\circ} \mathrm{C}$ for subsequent globule size analysis. Samples were then stored for $24 \mathrm{~h}$ at $4^{\circ} \mathrm{C}$ for whipping experiments.

\section{Emulsion Characterization}

The SFC of C1, C2, and C3 was estimated using a pulsed nuclear magnetic resonance (NMR; Minispec mq20, Bruker). A 2.0-mL aliquot of each cream sample was added to an NMR tube (ID $=10 \mathrm{~mm}$ ) and transferred to the NMR sample port set at $20^{\circ} \mathrm{C}$. Measurements were taken in triplicate based on AOCS Official Method Cd 16b-93 (AOCS, 1989). As the NMR was calibrated for fat and not cream (35 wt\% fat), the SFC values were adjusted relative to the TS in each cream $\left(\mathbf{S F C}_{\text {cream }}\right)$, which permitted comparisons between creams.

The fat globule size distribution of each emulsion was measured at room temperature using a Malvern Mastersizer 2000S laser diffraction unit (Malvern Instruments Inc.), with distilled water used as the dispersant material (refractive index 1.33). The refractive index of the milkfat globules was set at 1.47 . The volumeweighted average diameter $\left(\mathbf{D}_{4,3}\right)$ was reported for the globule size distributions.

The microstructure of the cream emulsions was examined at room temperature using brightfield and polarized light microscopy at a magnification of $320 \times$ (Zeiss Axiovert 200M inverted light microscope, Carl Zeiss). The microstructure of the whipped cream was observed using confocal laser scanning microscopy (LSM800 Zeiss). To highlight the milkfat, $0.01 \mathrm{wt} \%$ Nile Red (Sigma Aldrich) was dissolved in the churned milkfat before recombination with buttermilk. To make the aqueous phase more visible, a drop of a $0.1 \mathrm{wt} \%$ fluorescein aqueous solution (Sigma Aldrich) was added to the whipped sample before placing it in a concave microscope slide that was then covered with a coverslip.

\section{Whipping Properties}

Foaming of the control and recombined creams was performed using a gas canister equilibrated at $4^{\circ} \mathrm{C}$. A 250 -g sample of each cream was added to a metal siphon (ICO Trading Inc.) equipped with an 8-g nitrous oxide capsule and shaken 20 times by hand before being dispensed into tared Petri dishes. Four Petri dishes were filled, with the first discarded. For the remaining 3 dishes, excess foam was scraped off with a spatula to form a straight, level, smooth surface. The overrun was calculated as per Equation 1:

$$
\text { Overrun }=\frac{M_{\text {unwhipped }}-M_{\text {whipped }}}{M_{\text {whipped }}} \times 100,
$$

where $M_{\text {unwhipped }}$ is the mass of the unwhipped cream, and $M_{\text {whipped }}$ is the mass of the resulting foam (Smith et al., 1999).

Syneresis was measured as an indicator of foam stability. To do so, $20 \mathrm{~g}$ of whipped cream was placed in a steel wire sieve (8-cm diameter, holes of $\left.1 \mathrm{~mm}^{2}\right)$ over a beaker and transferred to an incubator (TC3-KE-100, Jeio Tech Co. Ltd.) set to $25^{\circ} \mathrm{C}$. The collected serum was weighed after $3 \mathrm{~h}$ of incubation. Syneresis was calculated as per Equation 2:

$$
\text { Syneresis }=\left(\frac{M_{s c}}{M_{w c}}\right) \times 100
$$

where $M_{s c}$ is the mass of the serum collected and $M_{w c}$ is the mass of the whipped cream after $3 \mathrm{~h}$ (Sajedi et al., 2014).

\section{Statistical Analysis}

Statistical analysis was based on the data from 3 independent experiments. Statistically significant differences in mean values were tested using ANOVA and a post hoc test for specific group mean differences. All statistical tests were performed at a 95\% level of significance. Principal component analysis (PCA) was used to discern differences in the fat globule size distribution of the control and recombined creams. Statistical analyses were performed using $\mathrm{R}$ (www.r-project.org) and OriginPRO 2015 (OriginLab Corporation).

\section{RESULTS}

\section{Initial Cream Properties}

The starting cream was tempered overnight at $4^{\circ} \mathrm{C}$ or $20^{\circ} \mathrm{C}$ to generate creams with higher and lower SFC (C1 and $\mathrm{C} 2$, respectively). A 1:1 blend of these 2 creams was used to yield C3. The $\mathrm{SFC}_{\text {cream }}$ values are shown in Table 1. Tempering did not alter the $\mathrm{D}_{4,3}$ of the 3 tempered creams compared with the control, given their similar average values at 4.1 to $4.7 \mu \mathrm{m}$. Polarized light microscopy expectedly revealed a higher number of intraglobule milkfat crystals in $\mathrm{C} 1$ followed by $\mathrm{C} 3$ and $\mathrm{C} 2$, which concurred with the $\mathrm{SFC}_{\text {cream }}$ results. Figure 2 shows representative brightfield (Figure 2A) and polarized light (Figure 2B) microscopy images of $\mathrm{C} 3$, where 

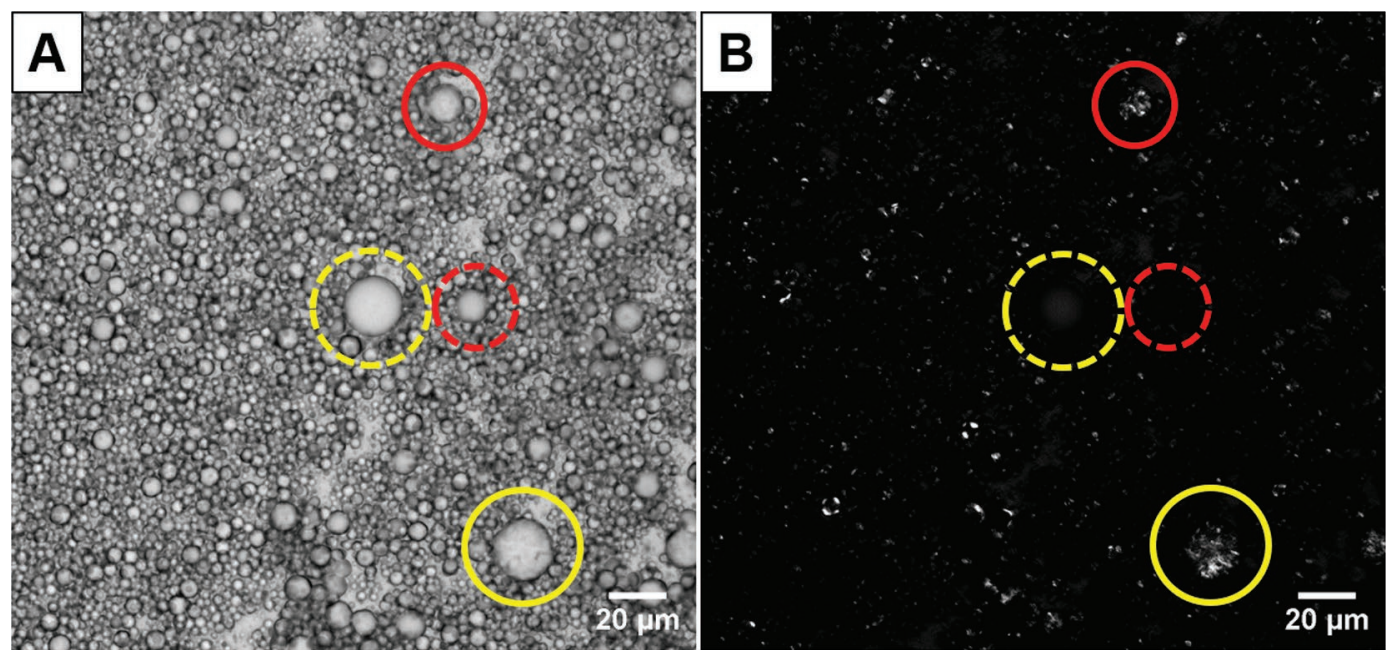

Figure 2. Representative images of cream 3. Circles of the same color highlight fat globules of similar sizes. Full circles reveal globules from cream 1, whereas dashed circles show globules from cream 2. (A) Brightfield (Zeiss Axiovert 200M inverted light microscope, Carl Zeiss, 320×); (B) polarized light.

the globules containing milkfat crystals originated in C1 (Supplemental Figure S1A; https://osf.io/p2dbv/, Andrade, 2021), whereas those devoid of crystals originated in C2 (Supplemental Figure S1B).

Tempering the creams to $4^{\circ} \mathrm{C}$ or $20^{\circ} \mathrm{C}$ did not alter their fat globule size distribution (Figure 3). All creams (i.e., control and tempered) showed primarily bimodal distributions comprising a main peak at $\sim 4 \mu \mathrm{m}$ (Briard et al., 2003; Michalski et al., 2004), along with a small peak at $\sim 0.2 \mu \mathrm{m}$ presumably made up of casein micelles and smaller globules (Dalgleish and Corredig, 2012).

\section{Churning and Recombination}

The point of subjecting the starting cream to 2 tempering treatments was to generate a butter and its corresponding buttermilk with different yields and compositions. The churning time was based on the lack of visual change in the butter mass produced and, as expected, differed among the creams: $1 \mathrm{~min}, 24 \mathrm{~s}( \pm$ $17 \mathrm{~s})$ for $\mathrm{C} 1,9 \mathrm{~min}, 32 \mathrm{~s}( \pm 31 \mathrm{~s})$ for $\mathrm{C} 2$, and $5 \mathrm{~min}$, $25 \mathrm{~s}( \pm 42 \mathrm{~s})$ for $\mathrm{C} 3$. The overall extraction yields (i.e., mass of buttermilk + butter) were $98.2 \pm 0.5 \%$ for $\mathrm{C} 1$, $97.7 \pm 0.8 \%$ for $\mathrm{C} 2$, and $96.4 \pm 4.5 \%$ for $\mathrm{C} 3$, with the small losses arising from incomplete separation. The butter and buttermilk yields for $\mathrm{C} 1$ and $\mathrm{C} 3$ were 45.4 $\pm 1.7 \%$ and $54.6 \pm 1.7 \%$, and $42.9 \pm 2.5 \%$ and $57.1 \pm$ 2. \%, respectively. Finally, C2 produced $34.1 \pm 1.3 \%$ butter and $65.9 \pm 1.3 \%$ buttermilk. The butter (\%) obtained was correlated $\left(\mathrm{R}^{2}=0.85\right)$ with $\mathrm{SFC}_{\text {cream }}$ as $\mathrm{C} 2$ showed the lowest $\mathrm{SFC}_{\text {cream }}$ and yield, followed by $\mathrm{C} 3$ and $\mathrm{C} 1$. Although no compositional analysis was performed, the higher $\mathrm{SFC}$ in $\mathrm{C} 1$ likely resulted in a higher proportion of disrupted milkfat globules, which altered the composition of the separated butter and buttermilk (Rombaut et al., 2006; Morin et al., 2007; Lopez et al., 2019).

The buttermilk from $\mathrm{C} 1$ showed the largest population of species under $1 \mu \mathrm{m}$ in diameter and a lower volume fraction of globules 2 to $7 \mu \mathrm{m}$ in diameter (Figure 3A). Its submicron particle population likely consisted of smaller milkfat globules, casein micelles, heat-induced protein aggregates, or MFGM fragments (Gassi et al., 2008; Lambert et al., 2016). The C2 buttermilk showed a fat globule size distribution similar to $\mathrm{C} 2$ before separation (Figure 3B), as fewer fat globules were disrupted given the lower butter yield. The small population of globules $>10 \mu \mathrm{m}$ in diameter may have resulted from the presence of small butter aggregates that were entrained with the buttermilk during drainage. The C3 buttermilk (Figure 3C) showed an inter-

Table 1. The $\mathrm{SFC}_{\text {cream }}$ and $\mathrm{D}_{4,3}$ of the control and tempered creams: data are described as the average of 3 independent experiments \pm SD

\begin{tabular}{lcc}
\hline Sample & $\mathrm{SFC}_{\text {cream }}(\%)$ & $\mathrm{D}_{4,3}(\mu \mathrm{m})^{2}$ \\
\hline Control & $-\overline{-}$ & $4.3 \pm 0.2$ \\
Cream 1 $\left(4^{\circ} \mathrm{C}\right)$ & $4.20 \pm 0.29^{\mathrm{a}}$ & $4.4 \pm 0.8$ \\
Cream 2 $\left(20^{\circ} \mathrm{C}\right)$ & $0.60 \pm 0.05^{\mathrm{b}}$ & $4.1 \pm 0.4$ \\
Cream 3 & $2.15 \pm 0.05^{\mathrm{c}}$ & $4.7 \pm 0.9$ \\
$\quad$ (blend of creams 1 and 2) & &
\end{tabular}

$\overline{{ }^{a} \mathrm{c}}$ Superscript letters denote significant differences based on ANOVA and Tukey HSD tests.

${ }^{1} \mathrm{SFC}_{\text {cream }}=$ solid fat content adjusted relative to the TS in each cream; $\mathrm{D}_{4,3}=$ volume-weighted average diameter for the globule size distributions.

${ }^{2}$ Kruskal-Wallis ANOVA. 


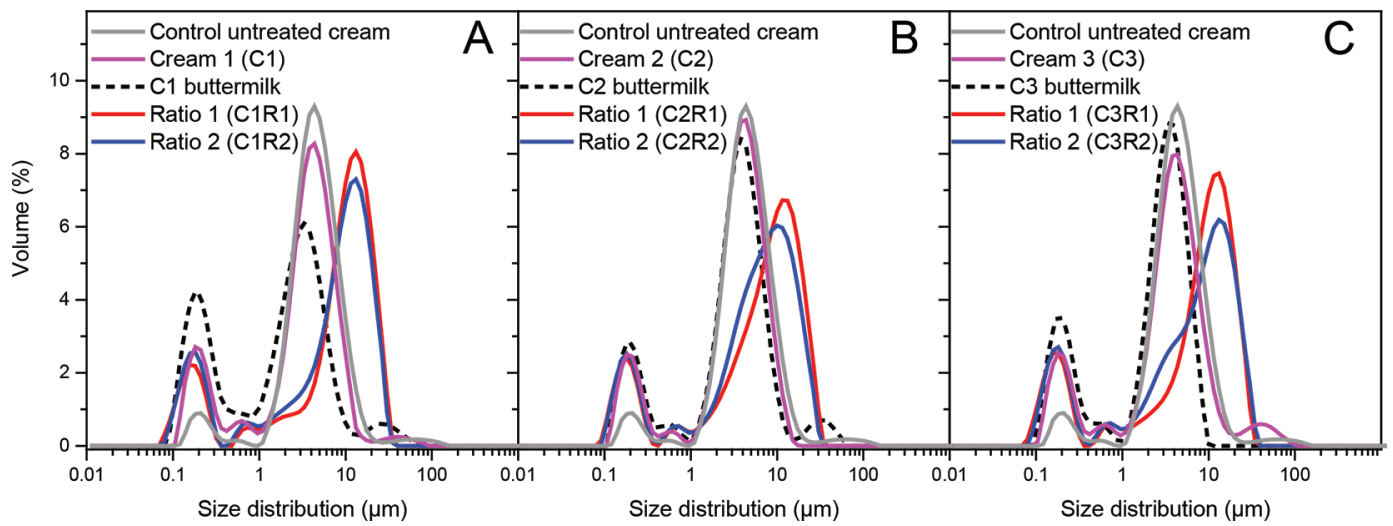

Figure 3. Milkfat globule size distributions of the control cream, the tempered creams before churning, their respective buttermilk obtained after churning, as well the recombined creams: (A) cream 1 (C1), (B) cream 2 (C2), and (C) cream 3 (C3). The 6 recombined creams are identified by cream thermal treatment $(\mathrm{C} 1, \mathrm{C} 2$, or $\mathrm{C} 3)$ and ratio $(\mathrm{R} 1$ or $\mathrm{R} 2)$ used.

mediate extraction yield as well as a milkfat globule size distribution similar to the initial C3 distribution.

Each cream was recombined at 2 buttermilk:butter ratios. For R1, the buttermilk and butter were recombined as per the yields obtained during churning, whereas for R2, $75 \mathrm{wt} \%$ of the churned butter was used, with extra buttermilk added to match the mass of R1. This approach, which reduced the total fat by $\sim 10 \%$, resulted in a recombined cream with less butter and more surface-active material than the $\mathrm{R} 1$ recombined cream.

Cream recombined at both $\mathrm{R} 1$ and $\mathrm{R} 2$ consisted of larger fat globules than in either of its initially tempered counterparts (Figure 3). Trimodal distributions were obtained for all recombined creams: a dominant peak centered at $\sim 11 \mu \mathrm{m}$ consisting of globules between 1 and $14 \mu \mathrm{m}$, a second population centered at $\sim 0.2$ $\mu \mathrm{m}$, and finally, a small population at 0.5 to $1 \mu \mathrm{m}$. Cream 2 at both R1 and R2 yielded the smallest average globule sizes, suggesting that this cream was the least damaged by tempering (Table $2 ; P<0.05$ ), with the $\mathrm{R} 1$ creams yielding higher $\mathrm{D}_{4,3}$ values than at $\mathrm{R} 2$. Overall, C2 R2 showed the lowest $\mathrm{D}_{4,3}$ value $(7.4 \pm 0.1$ $\mu \mathrm{m})$ and $\mathrm{C} 1 \mathrm{R} 1$ the highest $\mathrm{D}_{4,3}$ value $(9.6 \pm 0.1 \mu \mathrm{m})$. The smaller average $D_{4,3}$ values at $R 2$ versus $R 1$ for all creams were ascribed to the added MFGM lipids and proteins reintroduced into the recombined cream via the extra buttermilk.

Principal component analysis was used to further discern differences in the fat globule size distributions of the creams (Figure 4). Over $80 \%$ of the total variance of the milkfat globule distribution was explained by the first 2 principal components (PC), with a total of 5 $\mathrm{PC}$ accounting for $95 \%$ of the total calculated variance. Three distinct clusters associated with the recombined creams, tempered creams, and buttermilk were appar- ent in the score plot (Figure 4), with C1 R1 and C2 R2 revealed as most different along axis PC1. The corresponding loading plot showed that globules 7 to $30 \mu \mathrm{m}$ in diameter substantially contributed to the differences between the recombined creams via PC1 (Supplemental Figure S2, https://osf.io/p2dbv/, Andrade, 2021). Although PC2 explained less variation than PC1 (33 vs. $48 \%$ ), its loading plot demonstrated that globules 0.2 to $0.6 \mu \mathrm{m}$ in diameter were positively correlated with the positioning of the buttermilk in the score plot (right-hand cluster in Figure 4), whereas globules 2 to $10 \mu \mathrm{m}$ in diameter were negatively correlated (Supplemental Figure S2).

These findings strongly suggested that the tempering protocol applied to the creams led to recombined creams with disparate characteristics compared with the control cream, which could likely result in changes in foam formation and stability. As C1 and C2 at both recombination ratios were the treatments that led to

Table 2. The $\mathrm{D}_{4,3}$ values of the 6 recombined creams made with the 3 tempered creams (C1, C2, and $\mathrm{C} 3$ ), each recombined at 2 buttermilk: butter ratios ( $\mathrm{R} 1$ and $\mathrm{R} 2$ ); reported data are averages of 3 independent experiments $\pm \mathrm{SD}$

\begin{tabular}{ll}
\hline Recombined sample & $\mathrm{D}_{4,3}(\mu \mathrm{m})^{1}$ \\
\hline Cream 1 & \\
Ratio 1 (C1R1) & $9.6 \pm 0.1^{\mathrm{a}}$ \\
Ratio 2 (C1R2) & $9.0 \pm 0.3^{\mathrm{b}}$ \\
Cream 2 (C2R1) & $8.3 \pm 0.2^{\mathrm{c}}$ \\
Ratio 1 & $7.4 \pm 0.1^{\mathrm{d}}$ \\
Ratio 2 (C2R2) & \\
Cream 3 (C3R1) & $8.9 \pm 0.2^{\mathrm{b}}$ \\
Ratio 1 (C) & $8.5 \pm 0.2^{\mathrm{c}}$ \\
Ratio 2 (C3R2)
\end{tabular}

${ }^{\mathrm{a}-\mathrm{d}}$ Superscript letters denote significant differences (Kruskal-Wallis ANOVA and Conover-Bonferroni tests).

${ }^{1} \mathrm{D}_{4,3}=$ volume-weighted average diameter for the globule size distributions. 
the largest changes in globule size, we compared the aerosol whipping performance of these treatments with the control, untreated cream.

\section{Aerosol Whipping Properties}

Compared with the traditional bowl-and-whisk approach, the distinguishing factors of aerosol whipping used in this study are the higher overrun and poorer stability of the foam obtained (Wijnen, 1997). Stability in such foams is commonly improved by addition of emulsifiers and stabilizers to cream formulations (Wijnen, 1997). Recently, using the aerosol method, Blankart et al. (2020) were unable to form foams using recombined cream ( $30 \%$ milkfat, $\mathrm{D}_{4,3}$ of $\left.\sim 6 \mu \mathrm{m}\right)$ without adding emulsifiers. In contrast, our recombined creams resulted in foam formation without addition of any external ingredients.

Figure 5A shows a representative image of a whipped cream foam structure comprising air bubbles (in black) surrounded by fat (in red) and buttermilk (in green). Air bubbles were primarily covered by partially coalesced fat globules (dashed arrow; Sofian-Seng et al., 2017), though in some cases, some buttermilk surrounded the bubbles (solid arrows), which strongly suggested that both the globules and buttermilk components were responsible for bubble stabilization (Goff, 1997). Partial coalescence was also observed (Figure 5B), based on the presence of milkfat crystals inside the globules (Figure 5B arrows). Similar foam structures were observed in all samples with air bubbles 20 to $80 \mu \mathrm{m}$ in diameter present (Supplemental Figure S3, osf.io/ p2dbv, Andrade, 2021), but with the R2 creams resulting in somewhat larger bubbles.

The overrun of the recombined creams ranged from 146 to $200 \%$, which was significantly higher than the control $(87 \pm 3 \% ; P<0.05$; Figure 6$)$. The R2 recombined creams, which likely contained less total fat and a higher proportion of surface-active material from the MFGM, produced higher overrun than at R1.

The increased overrun of the recombined creams versus the control cream likely resulted from their larger-sized fat globules (Table 2). Using an overhead stirrer for foam formation, Edén and coworkers (2016) similarly showed that larger milkfat globules led to increased overrun. In addition, larger globules tend to

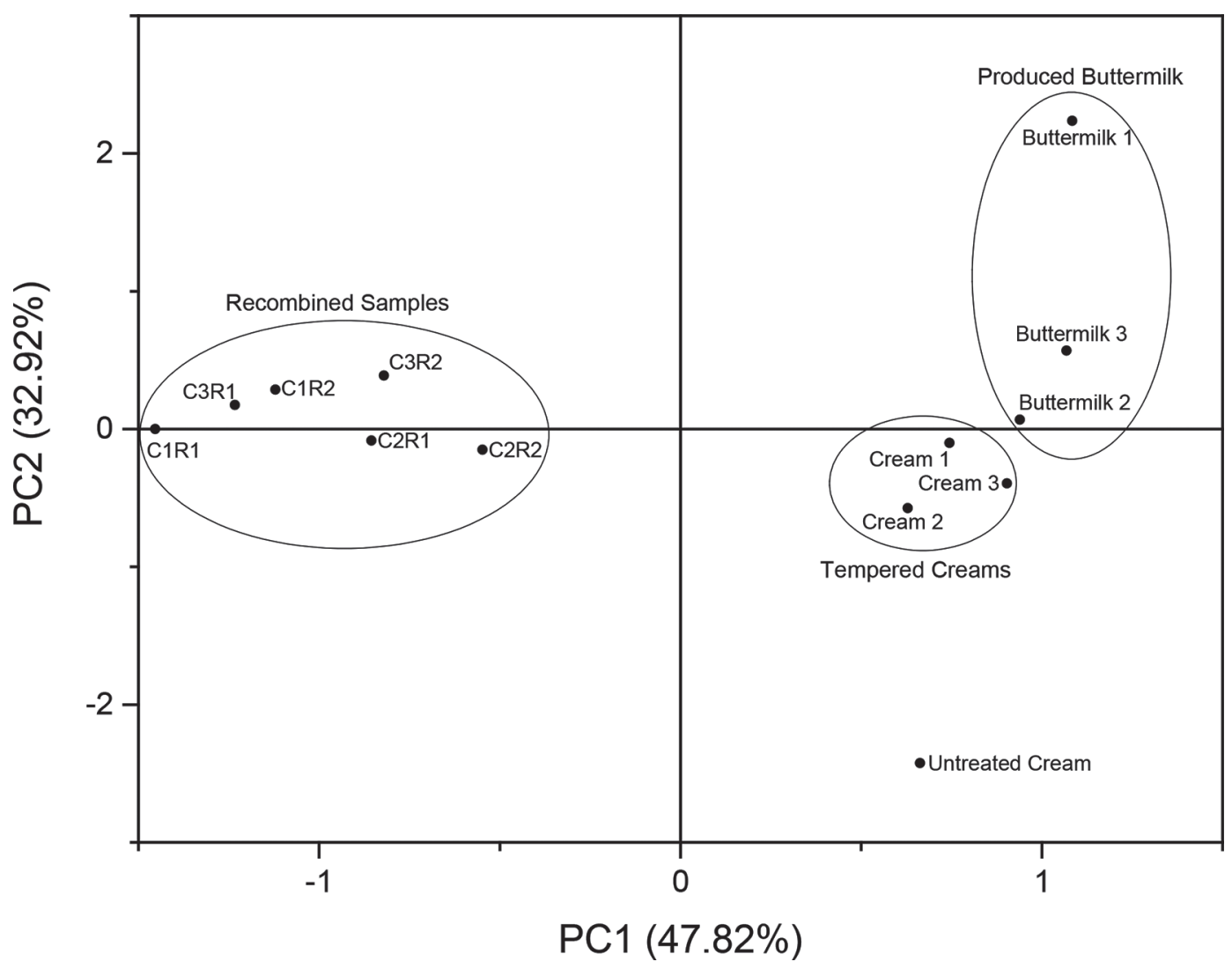

Figure 4. Principal component (PC) analysis score plot of the fat globule size distributions of the tempered creams, buttermilk, and recombined creams (cream $1=\mathrm{C} 1$, cream $2=\mathrm{C} 2$, and cream $3=\mathrm{C} 3$ ) at ratios $\mathrm{R} 1$ and $\mathrm{R} 2$. 

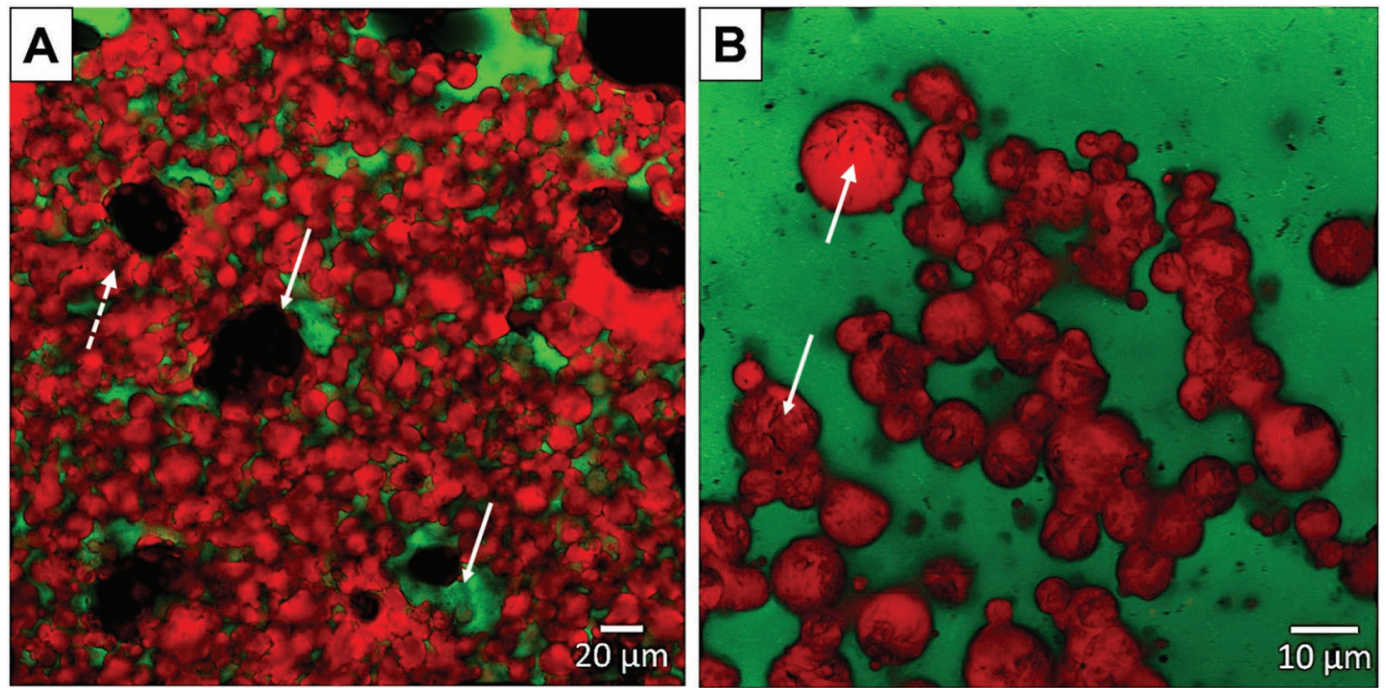

Figure 5. Representative confocal micrographs of whipped cream (cream 1, ratio 1). (A) Whipped cream structure at 200×; (B) partial coalescence of fat globules at $630 \times$. Dashed and solid arrows in (A) point to bubbles stabilized by globules, serum, or both. Arrows in (B) point to fat crystals visible within the globules. Red $=$ Nile red-stained milkfat; green $=$ fluorescein-stained aqueous phase; black $=$ air bubbles.

contain more or larger (or both) milkfat crystals once cooled, which may contribute to higher overrun (Lopez et al., 2002; Truong et al., 2014a,b). In a study on recombined creams, addition of MFGM material isolated from buttermilk resulted in increased cream foam formation (Phan et al., 2014).

Syneresis only occurred with the R2 recombined creams, as no buttermilk leakage was observed with the control or R1-based creams (Figure 6). The presence

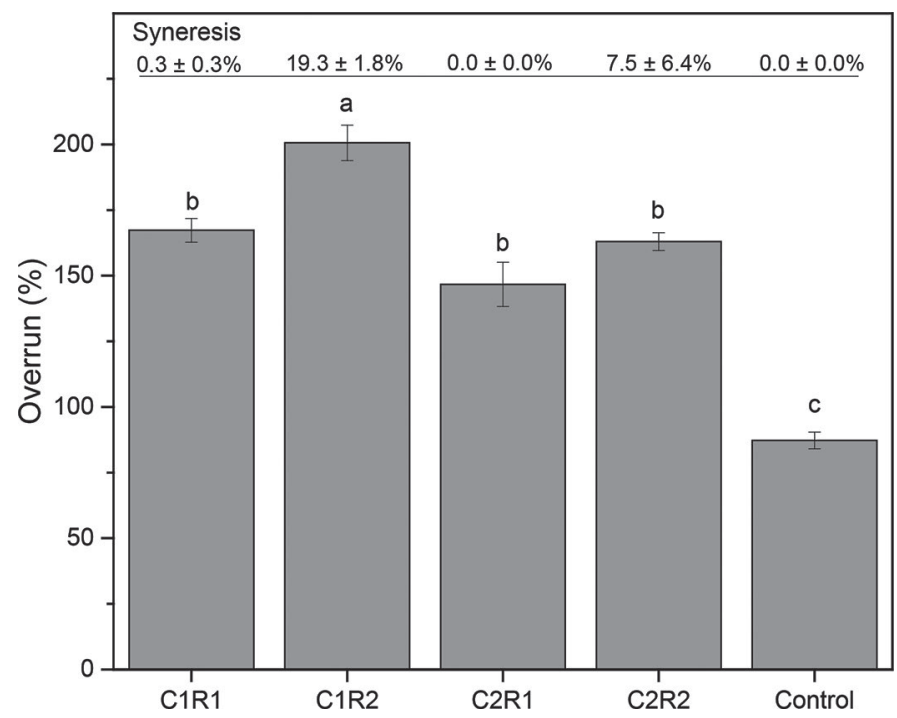

Figure 6. Whipping properties of cream $1(\mathrm{C} 1)$ and cream $2(\mathrm{C} 2)$ at both recombination ratios (R1 and $\mathrm{R} 2)$. Letters denote significant differences among the groups (ANOVA and Tukey HSD). Error bars represent the SD. of more buttermilk in the $\mathrm{R} 2$ recombined creams may have contributed to the enhanced whipping properties as whey proteins show excellent foamability (Truong et al., 2014a). Images of the $\mathrm{R} 2$ recombined creams revealed the presence of more buttermilk surrounding the air bubbles (Supplemental Figure S3). Speculatively, it is possible that the lower SFC resulted in a sparser network between partially coalesced fat globules, which permitted the flow of the liquid between the air bubbles, resulting in serum leakage.

Considering the whipping properties as an exemplary property, although differences were obtained with the recombination, the data showed once again that the behavior of the recombined creams was unlike that of the original untreated cream, regardless of how it was split and recombined. Even though the components of native MFGM were present in the samples (even in excess), their combination while forming the new globule surface was likely different from the original, reinforcing the view that many dairy products owe their unique properties to MFGM structure rather than MFGM components, and that these structures can be irreversibly and easily damaged during processing (Evers et al., 2008).

\section{CONCLUSIONS}

This study investigated cream structuring via pretempering to different SFC, as well as characterization of recombined cream with or without addition of $25 \%$ extra buttermilk, and how this approach affected aerosol whipped cream formation and stability. Churning of 
cream pretempered to different SFC was used to separate into butter and buttermilk with different yields. Although statistically significant differences in milkfat globule size distributions were obtained, the whipping behavior and associated microstructure of foams made with all recombined creams were similar, but dissimilar from that of the original, untreated cream. This study, as in others in the past, showed that simply recombining separated cream and expecting the functionality of the native cream was not possible. Future investigation will focus on approaches to reassemble recombined cream in a manner that more closely mimics the structure and organization of the MFGM in untreated cream.

\section{ACKNOWLEDGMENTS}

We gratefully acknowledge the Fonterra Research and Development Centre (Palmerston North, NZ), especially Paul Andrewes, Christina Coker, and Sheelagh Hewitt, for partnership and funding of this research. The Natural Sciences and Engineering Research Council of Canada (NSERC) is also acknowledged for funding support. The authors have not stated any conflicts of interest.

\section{REFERENCES}

Andrade, J. 2021. Whipping properties of recombined, additive-free creams (supplemental information). Accessed Feb. 16, 2021. https://osf.io/p2dbv/.

AOCS. 1989. Method Cd 16b-93 in Official Methods and Recommended Practices of the American Oil Chemists' Society. 4th ed. D. Firestone, ed. AOCS Press.

Blankart, M., C. Kratzner, K. Link, C. Oellig, W. Schwack, and J. Hinrichs. 2020. Technical emulsifiers in aerosol whipping cream - Compositional variations in the emulsifier affecting emulsion and foam properties. Int. Dairy J. 102:104578. https://doi.org/10 .1016/j.idairyj.2019.104578.

Boode, K., P. Walstra, and A. E. A. de Groot-Mostert. 1993. Partial coalescence in oil-in-water emulsions 2. Influence of the properties of the fat. Colloids Surf. A Physicochem. Eng. Asp. 81:139-151. https://doi.org/10.1016/0927-7757(93)80240-F.

Briard, V., N. Leconte, F. Michel, and M. C. Michalski. 2003. The fatty acid composition of small and large naturally occurring milk fat globules. Eur. J. Lipid Sci. Technol. 105:677-682. https://doi .org/10.1002/ejlt.200300812.

Brooker, B.E., M. Anderson, and A.T. Andrews. 1986. The development of structure in whipped cream. J. Food Struct. 5:277-285.

Buldo, P., J. J. K. Kirkensgaard, and L. Wiking. 2013. Crystallization mechanisms in cream during ripening and initial butter churning. J. Dairy Sci. 96:6782-6791. https://doi.org/10.3168/jds.2012 -6066 .

Corredig, M., R. R. Roesch, and D. G. Dalgleish. 2003. Production of a novel ingredient from buttermilk. J. Dairy Sci. 86:2744-2750. https://doi.org/10.3168/jds.S0022-0302(03)73870-3.

Dalgleish, D. G., and M. Corredig. 2012. The structure of the casein micelle of milk and its changes during processing. Annu. Rev. Food Sci. Technol. 3:449-467. https://doi.org/10.1146/annurev-food -022811-101214.

Dickinson, E. 2009. Hydrocolloids and emulsion stability. Chapter 2 in Handbook of Hydrocolloids. 2nd ed. G. O. Phillips and P. A. Williams, ed. Woodhead Publishing Limited.
Edén, J., P. Dejmek, R. Löfgren, M. Paulsson, and M. Glantz. 2016. Native milk fat globule size and its influence on whipping properties. Int. Dairy J. 61:176-181. https://doi.org/10.1016/j.idairyj 2016.06.004.

Evers, J. M. 2004a. The milkfat globule membrane - Methodologies for measuring milkfat globule (membrane) damage. Int. Dairy J. 14:747-760. https://doi.org/10.1016/j.idairyj.2004.01.006.

Evers, J. M. 2004b. The milkfat globule membrane - Compositional and structural changes post secretion by the mammary secretory cell. Int. Dairy J. 14:661-674. https://doi.org/10.1016/j.idairyj .2004.01.005.

Evers, J. M., R. G. Haverkamp, S. E. Holroyd, G. B. Jameson, D. D. S. Mackenzie, and O. J. McCarthy. 2008. Heterogeneity of milk fat globule membrane structure and composition as observed using fluorescence microscopy techniques. Int. Dairy J. 18:1081-1089. https://doi.org/10.1016/j.idairyj.2008.06.001.

Fox, P. F., and P. L. H. McSweeney. 2006. Advanced Dairy Chemistry Volume 2: Lipids. 3rd ed.

Fuller, G. T., T. Considine, M. Golding, L. Matia-Merino, and A. MacGibbon. 2015a. Aggregation behavior of partially crystalline oil-in-water emulsions: Part II - Effect of solid fat content and interfacial film composition on quiescent and shear stability. Food Hydrocoll. 51:23-32. https://doi.org/10.1016/j.foodhyd.2015.03 .032.

Fuller, G. T., T. Considine, M. Golding, L. Matia-Merino, A. MacGibbon, and G. Gillies. 2015b. Aggregation behavior of partially crystalline oil-in-water emulsions: Part I - Characterization under steady shear. Food Hydrocoll. 43:521-528. https://doi.org/10 .1016/j.foodhyd.2014.07.032.

Gassi, J. Y., M. H. Famelart, and C. Lopez. 2008. Heat treatment of cream affects the physicochemical properties of sweet buttermilk. Dairy Sci. Technol. 88:369-385. https://doi.org/10.1051/dst: 2008006.

Goff, H. D. 1997. Instability and partial coalescence in whippable dairy emulsions. J. Dairy Sci. 80:2620-2630. https://doi.org/10 .3168/jds.S0022-0302(97)76219-2.

Hotrum, N. E., M. A. C. Stuart, T. van Vliet, S. F. Avino, and G. A. van Aken. 2005. Elucidating the relationship between the spreading coefficient, surface-mediated partial coalescence and the whipping time of artificial cream. Colloids Surf. A Physicochem. Eng. Asp. 260:71-78. https://doi.org/10.1016/j.colsurfa.2005.03.004.

Lambert, S., N. Leconte, M. Blot, F. Rousseau, B. Robert, B. Camier, J. Y. Gassi, C. Cauty, C. Lopez, and G. Gésan-Guiziou. 2016. The lipid content and microstructure of industrial whole buttermilk and butter serum affect the efficiency of skimming. Food Res. Int 83:121-130. https://doi.org/10.1016/j.foodres.2016.03.002.

Lopez, C., C. Bourgaux, P. Lesieur, S. Bernadou, G. Keller, and M. Ollivon. 2002. Thermal and structural behavior of milk fat. 3. Influence of cooling rate and droplet size on cream crystallization. J. Colloid Interface Sci. 254:64-78. https://doi.org/10.1006/jcis.2002 .8548 .

Lopez, C., C. Cauty, and F. Guyomarc'h. 2019. Unraveling the complexity of milk fat globules to tailor bioinspired emulsions providing health benefits: The key role played by the biological membrane. Eur. J. Lipid Sci. Technol. 121:1800201. https://doi.org/10 .1002 /ejlt.201800201.

Méndez-Velasco, C., and D. Goff. 2011. Enhancement of fat colloidal interactions for the preparation of ice cream high in unsaturated fat. Int. Dairy J. 21:540-547. https://doi.org/10.1016/j.idairyj 2011.03.008.

Michalski, M. C., M. Ollivon, V. Briard, N. Leconte, and C. Lopez. 2004. Native fat globules of different sizes selected from raw milk: Thermal and structural behavior. Chem. Phys. Lipids 132:247261. https://doi.org/10.1016/j.chemphyslip.2004.08.007.

Moens, K., A. K. M. Masum, and K. Dewettinck. 2016. Tempering of dairy emulsions: Partial coalescence and whipping properties. Int. Dairy J. 56:92-100. https://doi.org/10.1016/j.idairyj.2016.01.007.

Morin, P., R. Jiménez-Flores, and Y. Pouliot. 2007. Effect of processing on the composition and microstructure of buttermilk and its milk fat globule membranes. Int. Dairy J. 17:1179-1187. https:// doi.org/10.1016/j.idairyj.2007.03.010. 
Panchal, B. R., T. Truong, S. Prakash, N. Bansal, and B. Bhandari. 2017. Effect of fat globule size on the churnability of dairy cream. Food Res. Int. 99:229-238. https://doi.org/10.1016/j.foodres.2017 .05 .027 .

Phan, T. T. Q., K. Moens, T. T. Le, P. Van der Meeren, and K. Dewettinck. 2014. Potential of milk fat globule membrane enriched materials to improve the whipping properties of recombined cream. Int. Dairy J. 39:16-23. https://doi.org/10.1016/j.idairyj.2014.05.003.

Rombaut, R., J. V Camp, and K. Dewettinck. 2006. Phospho- and sphingolipid distribution during processing of milk, butter and whey. Int. J. Food Sci. Technol. 41:435-443. https://doi.org/10 $.1111 / \mathrm{j} .1365-2621.2005 .01091 . x$.

Sajedi, M., A. Nasirpour, J. Keramat, and S. Desobry. 2014. Effect of modified whey protein concentrate on physical properties and stability of whipped cream. Food Hydrocoll. 36:93-101. https:// doi.org/10.1016/j.foodhyd.2013.09.007.

Scott, L. L., S. E. Duncan, S. S. Sumner, and K. M. Waterman. 2003. Physical properties of cream reformulated with fractionated milk fat and milk-derived components. J. Dairy Sci. 86:3395-3404. https://doi.org/10.3168/jds.S0022-0302(03)73943-5.

Singh, H., and S. Gallier. 2017. Nature's complex emulsion: The fat globules of milk. Food Hydrocoll. 68:81-89. https://doi.org/10 .1016/j.foodhyd.2016.10.011.

Smith, A. K., H. D. Goff, and Y. Kakuda. 1999. Whipped cream structure measured by quantitative stereology. J. Dairy Sci. 82:16351642. https://doi.org/10.3168/jds.S0022-0302(99)75392-0.

Sofian-Seng, N. S., M. Golding, K. Goh, P. Janssen, and S. J. Lee. 2017. In situ enzymatic synthesis of polar lipid emulsifiers in the preparation and stabilisation of aerated food emulsions. Food Biophys. 12:323-338. https://doi.org/10.1007/s11483-017-9488-1.
Tamime, A. Y. 2009. Dairy Fats and Related Products. A. Y. Tamime, ed. Wiley-Blackwell.

Thivilliers, F., E. Laurichesse, H. Saadaoui, F. Leal-Calderon, and V. Schmitt. 2008. Thermally induced gelling of oil-in-water emulsions comprising partially crystallized droplets: The impact of interfacial crystals. Langmuir 24:13364-13375. https://doi.org/10.1021/ la802521f.

Truong, T., N. Bansal, and B. Bhandari. 2014a. Effect of emulsion droplet size on foaming properties of milk fat emulsions. Food Bioprocess Technol. 7:3416-3428. https://doi.org/10.1007/s11947 -014-1352-4.

Truong, T., N. Bansal, R. Sharma, M. Palmer, and B. Bhandari. 2014b. Effects of emulsion droplet sizes on the crystallisation of milk fat. Food Chem. 145:725-735. https://doi.org/10.1016/j .foodchem.2013.08.072.

van Lent, K., C. T. Le, B. Vanlerberghe, and P. Van der Meeren. 2008. Effect of formulation on the emulsion and whipping properties of recombined dairy cream. Int. Dairy J. 18:1003-1010. https://dol .org/10.1016/j.idairyj.2008.04.002.

Wijnen, M. E. 1997. Instant Foam Physics: Formation and Stability of Aerosol Whipped Cream. Wageningen University.

Wasan, D., W. Xu, A. Dutta, and A. Nikolov. 2004. Structure and stability of aerated food emulsions. Chapter 6 in Food Emulsions. 4th ed. S. E. Friberg, K. Larsson, and J. Sjöblom, ed. Marcel Dekker.

\section{ORCIDS}

J. Andrade (ำ https://orcid.org/0000-0001-7711-5306

D. Rousseau (ㄴ) https://orcid.org/0000-0003-1482-6869 